\title{
PERANCANGAN SOFTWARE AS A SERVICE (SAAS) UNTUK SISTEM PELAYANAN KESEHATAN IBU DAN ANAK (PKIA) PADA PUSKESMAS SE-KOTA MATARAM BERBASIS CLOUD COMPUTING
}

\author{
Andy Hidayat Jatmika ${ }^{1}$, Royana Afwani ${ }^{2}$, Nadiyasari Agitha ${ }^{3}$ \\ ${ }^{1,2,3}$ Program Studi Teknik Informatika, Fakultas Teknik, Universitas Mataram \\ Email: 1andy@unram.ac.id, ${ }^{2}$ royana@unram.ac.id, ${ }^{3}$ nadiya@unram.ac.id \\ (Naskah masuk: 07 Januari 2019, diterima untuk diterbitkan: 02 Oktober 2019)
}

\begin{abstract}
Abstrak
Saat ini sistem pengolahan data pasien layanan KIA di semua puskesmas di kota Mataram masih dikerjakan dengan cara konvensional atau belum memanfaatkan teknologi sistem informasi. Permasalahan yang muncul dari pihak puskesmas adalah lambatnya proses pelayanan pasien yaitu dalam hal pendataan pasien dan pencarian data pasien, serta tingginya tingkat kesalahan dalam pengolahan data pasien misalnya data pendaftaran, data pemeriksaan, dan data rujukan. Permasalahan dari sisi pasien adalah pasien harus datang ke puskesmas jika ingin mendaftar, pasien harus mendaftar sebagai pasien baru lagi jika ke puskesmas yang berbeda, pasien masih menggunakan buku KIA untuk mendapatkan informasi dan melihat catatan hasil konseling yang memiliki resiko rusak atau hilang, serta pasien kesulitan untuk melakukan monitoring terhadap perawatan kesehatannya. Keberadaan teknologi cloud computing dengan layanan Software as a Service (SaaS) dapat memberikan solusi untuk permasalahan tersebut. SaaS merupakan model bisnis untuk menyampaikan aplikasi dalam bentuk layanan. SaaS untuk sistem PKIA akan sangat berguna bagi puskesmas dalam mengelola data pasien, sedangkan bagi pasien akan mempermudah mendapatkan informasi dan mempercepat proses layanan. Tujuan penelitian ini adalah membuat rancangan SaaS untuk sistem PKIA dimana nantinya seluruh Puskesmas di Kota Mataram yang telah tergabung dalam community cloud computing memiliki keseragaman sistem dalam mengelola data pasien dan dapat diakses dari puskesmas mana saja. Terdapat dua metode yang digunakan pada penelitian ini yaitu (1) analisis layanan bisnis, (2) analisis kebutuhan sistem, dan (3) analisis service oriented architecture. Data yang digunakan dalam penelitian ini diambil saat dilakukan observasi langsung dan pengumpulan data di puskesmas wilayah Mataram. Hasil akhir penelitian ini berupa (1) prototype model layanan bisnis PKIA puskesmas yang digambarkan dalam bentuk use case diagram sebagai bagian dari layanan SaaS serta (2) prototype web service. Berdasarkan hasil wawancara dengan pihak Puskesmas yang terdiri dari bidan dan petugas, hasil rancangan ini telah sesuai dengan apa yang diharapkan. Perancangan ini diharapkan dapat dijadikan dasar dalam implementasi perangkat lunak sistem PKIA puskesmas se-Kota Mataram berbasis cloud SaaS.
\end{abstract}

Kata kunci: puskesmas, pelayanan kesehatan ibu dan anak (PKIA), cloud computing, software as a service (SaaS)

\section{DESIGN OF SOFTWARE AS A SERVICE (SAAS) FOR MATERNAL AND CHILD HEALTH SERVICES SYSTEM ON PUBLIC HEALTH CENTER IN MATARAM CITY BASED ON CLOUD COMPUTING}

\begin{abstract}
Currently, patient data processing system of PKIA services in public health centers in Mataram city is still doing conventional way that is not yet utilize information technology. The problems that arise from public health centers are: a long service process which includes patient data collection and patient data retrieval, and the number of errors in the processing of patient data, such as registration data, examination data, and referral data. Problems from the patient that the patient must come if will do the registration, must register as new patient if to the different public health centers, still use the manual book to get information and see the record of counseling results that have the risk of damaged or lost, and difficulty in monitoring health care. The existence of cloud computing technology with Software as a Service (SaaS) can provide solutions to these problem. SaaS is a business model for delivering applications in the form of services. SaaS for PKIA will be very useful for public health center to manage patient data, patient will be more efficient easier to get service and get information. The purpose of this research is to design the SaaS for PKIA system where the public health center in Mataram City which is incorporated in community cloud has uniform system in managing data. This research uses three methods: (1) business service analysis, (2) system requirement analysis, and (3) service oriented architecture analysis. The data used in this research was taken when doing observation and data collection at public health center of Mataram city. The results of this research are (1) prototype of PKIA business service model which is described in the form of use case diagram as part of SaaS service and (2) prototype of web service. Based on the results of interviews conducted with the Public Health Center, the results of this design were as expected. This design can be used as a basis in the implementation of software on the system of PKIA based on cloud SaaS.
\end{abstract}

Keywords: public health center, maternal and child health services, cloud computing, software as a service (SaaS 


\section{PENDAHULUAN}

Banyaknya kunjungan dan informasi kesehatan selama kehamilan sampai dengan setelah melahirkan membuat Pelayanan Kesehatan Ibu dan Anak (PKIA) menjadi pelayanan yang paling sibuk di sebuah puskesmas. Melihat banyaknya kunjungan dan informasi kesehatan selama kehamilan sampai dengan setelah melahirkan, dan untuk meningkatkan akses masyarakat terhadap pelayanan PKIA yang berkualitas maka peranan tenaga kesehatan PKIA dan jaringannya sebagai institusi yang menyelenggarakan pelayanan kesehatan di jenjang pertama yang terlibat langsung dengan masyarakat menjadi sangat penting (Afwani, 2017). Trend saat ini adalah dapat memberikan berbagai macam layanan secara terdistribusi dan pararel secara remote dan dapat berjalan di berbagai device, dan teknologinya dapat dilihat dari berbagai macam teknologi yang digunakan dari proses informasi yang dilakukan secara outsourcing sampai dengan penggunaan eksternal data center (Balboni, 2009).

Saat ini sistem pengolahan data pasien layanan KIA di semua puskesmas di kota Mataram masih dikerjakan dengan cara konvensional atau belum memanfaatkan teknologi informasi. Permasalahan yang muncul dari pihak puskesmas adalah (1) lambatnya proses pelayanan pasien, yaitu dalam hal pendataan pasien dan pencarian data pasien, serta (2) tingginya tingkat kesalahan dalam pengolahan data pasien misalnya data pendaftaran, data pemeriksaan, dan data rujukan. Permasalahan dari sisi pasien adalah (1) pasien harus datang ke puskesmas jika ingin mendaftar, (2) pasien harus mendaftar sebagai pasien baru lagi jika ke puskesmas yang berbeda, (3) pasien masih menggunakan buku KIA untuk mendapatkan informasi dan melihat catatan hasil konseling yang memiliki resiko rusak atau hilang, dan (4) pasien kesulitan untuk melakukan monitoring terhadap perawatan kesehatannya.

Keberadaan teknologi cloud computing dengan layanan Software as a Service (SaaS) dapat memberikan solusi untuk permasalahan tersebut. Alasan pemilihan Cloud computing pada penelitian ini adalah karena teknologi ini memungkinkan akses data dari mana saja dan menggunakan perangkat fixed atau mobile device.

Layanan utama yang disediakan oleh cloud computing dapat dibagi menjadi 3 bagian, diantaranya (Armbrust, 2010):

1. IaaS (Infrastructure as a Service), kemampuan dalam menetapkan ketersediaan perangkat keras kepada konsumen meliputi: processing, storage, networks and other fundamental computing resource. Termasuk operating systems and applications.

2. PaaS (Platform as a Service), kemampuan dalam menyediakan layanan kepada konsumen untuk dapat membangun aplikasi yang mendukung kedalam infrastruktur cloud computing dengan menggunakan bahasa pemrograman sehingga aplikasi tersebut dapat berjalan pada platform yang telah disediakan.

3. SaaS (software as a service), kemampuan dalam menyediakan layanan yang ditujukan kepada konsumen untuk dapat menjalankan aplikasi diatas infrastruktur cloud computing yang telah disediakan.

SaaS merupakan model bisnis untuk menyampaikan aplikasi dalam bentuk layanan. SaaS untuk sistem PKIA akan sangat berguna bagi puskesmas dalam mengelola data pasien, sedangkan bagi pasien akan mempermudah mendapatkan informasi ataupun memonitoring tentang perawatan kesehatannya secara real time dan mempercepat proses layanan.

Penggunaan SaaS akan menghasilkan berbagai manfaat seperti penghematan biaya, ketangkasan (agility) yang lebih baik, dan mempercepat penyampaian layanan kepada pengguna, serta peningkatan fleksibilitas dalam berbagai skala untuk mendukung lebih banyak pengguna yang diperlukan. Karakteristik SaaS adalah bersifat multitenant sehingga satu aplikasi dapat digunakan oleh berbagai puskesmas. Arsitektur SaaS dapat dilihat pada Gambar 1.

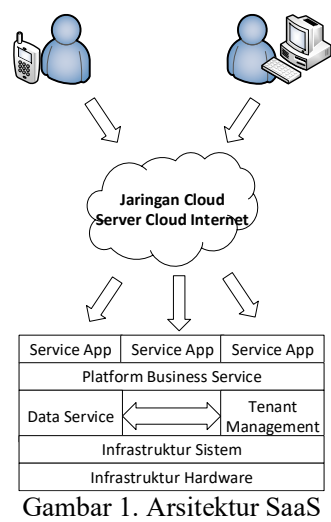

Penelitian terkait yang pernah dilakukan yaitu perancangan dan implementasi layanan SaaS pada sistem informasi Rumah Sakit sebagai pelayanan kesehatan, mengatakan bahwa hasil penelitian yang dilakukan mampu menciptakan keseragaman dan memudahkan dalam mengolah data serta menyimpan informasi data Rumah Sakit (Kusdiana, 2014). Penelitian serupa yang telah dilakukan oleh yaitu melakukan perancangan arsitektur software as a service (SaaS) pada layanan Rumah Sakit memberi kesimpulan mengenai hasil penelitian yaitu dengan adanya layanan SaaS ternyata mampu mengurangi biaya investasi baik hardware maupun software serta menyelesaikan masalah keterbatasan sumber daya manusia dalam bidang teknologi informasi (Toni, 2012). Penelitian dengan melakukan implementasi layanan SaaS pada sistem layanan klinik sebagai bagian dari fasilitas kesehatan juga pernah dilakukan, dimana hasil penelitian tersebut mengatakan bahwa dengan mengimplementasikan layanan SaaS mampu mengurangi biaya investasi dan dapat menjadi 
alternatif baru dalam pelayanan kesehatan (Ayuningsih, dkk, 2015).

Tujuan dari penelitian ini adalah membuat rancangan SaaS untuk sistem PKIA, dimana nantinya seluruh Puskesmas di Kota Mataram yang telah tergabung dalam community cloud memiliki keseragaman sistem dalam mengelola data pasien (Jatmika \& Afwani, 2018). Data pasien akan tersimpan di data center sehingga dapat diakses dari Puskesmas mana saja. Bagi pasien akan mempermudah mendapatkan informasi ataupun memonitor tentang perawatan kesehatannya dan mempercepat proses layanan.

Data yang digunakan dalam penelitian ini diambil saat dilakukan observasi langsung dan pengumpulan data di puskesmas wilayah Kota Mataram. Hasil akhir penelitian ini berupa prototype model layanan (proses) bisnis PKIA puskesmas yang digambarkan dalam bentuk use case diagram (Sukamto and Shalahuddin, 2018) sebagai bagian dari layanan SaaS serta prototype web service. Perancangan ini diharapkan dapat dijadikan dasar dalam implementasi perangkat lunak sistem PKIA puskesmas se-Kota Mataram yang berbasis cloud SaaS.

\section{METODE}

Terdapat 3 (tiga) metode yang digunakan pada penelitian ini yaitu (1) analisis layanan bisnis, (2) analisis kebutuhan sistem, dan (3) analisis service oriented architecture. Pembahasan akan dijelaskan pada sub bab 2.1, sub bab 2.2, dan sub bab 2.3.

\subsection{Analisis Layanan (Proses) Bisnis}

Pada bagian ini akan dianalisis mengenai layanan (proses) bisnis PKIA puskesmas. Analisis dilakukan secara deskripstif kualitatif dengan melakukan pengamatan dan wawancara ke lapangan.

Terdapat beberapa layanan bisnis baik yang bersifat fungsional atau non-fungsional yang didapat dari dokumen-dokumen yang diberikan pada saat kunjungan ke lapangan. Berdasarkan dokumen tersebut terutama pada buku pedoman Pemantauan Wilayah Setempat Kesehatan Ibu Dan Anak (PWSKIA), terdapat Sembilan (9) kegiatan atau pelayanan pokok pada PKIA, yang terlihat pada Tabel 1.

\begin{tabular}{ccc}
\multicolumn{2}{c}{ Tabel 1. Layanan bisnis PKIA } \\
\hline no & $\begin{array}{c}\text { layanan } \\
\text { bisnis }\end{array}$ & \multicolumn{1}{c}{ deskripsi layanan } \\
\hline 1 & Antenatal & $\begin{array}{l}\text { Peningkatan pelayanan antenatal sesuai } \\
\text { standar bagi seluruh ibu hamil. } \\
\text { Peningkatan pertolongan persalinan oleh } \\
\text { tenaga kesehatan kompeten diarahkan ke } \\
\text { fasilitas kesehatan. }\end{array}$ \\
2 & Persalinan \\
3 & Ibu Nifas & $\begin{array}{l}\text { Peningkatan pelayanan bagi seluruh ibu } \\
\text { nifas sesuai standar. } \\
\text { Peningkatan pelayanan bagi seluruh } \\
\text { neonatus sesuai standar. } \\
\text { Peningkatan pelayanan bagi seluruh } \\
\text { PONED neonatus sesuai standar }\end{array}$ \\
\hline 5 & Neonatus & $\begin{array}{l}\text { PONED } \\
\text { Neonatus }\end{array}$
\end{tabular}

\begin{tabular}{|c|c|c|}
\hline no & $\begin{array}{c}\text { layanan } \\
\text { bisnis }\end{array}$ & deskripsi layanan \\
\hline & PONED & Peningkatan pelayanan bagi seluruh \\
\hline 6 & Obstetri & PONED obstetri sesuai standar \\
\hline 7 & $\begin{array}{l}\text { Kesehatan } \\
\text { Bayi }\end{array}$ & $\begin{array}{l}\text { Peningkatan pelayanan bagi seluruh } \\
\text { bayi sesuai standar. }\end{array}$ \\
\hline 8 & $\begin{array}{l}\text { Kesehatan } \\
\text { Balita }\end{array}$ & $\begin{array}{l}\text { Peningkatan pelayanan bagi seluruh } \\
\text { balita sesuai standar. }\end{array}$ \\
\hline 9 & $\begin{array}{l}\text { KB } \\
\text { Berkualitas }\end{array}$ & Peningkatan pelayanan KB sesuai standar \\
\hline
\end{tabular}

\subsection{Analisis Kebutuhan Sistem}

Tabel 2 merupakan analisis kebutuhan sistem PKIA pada puskesmas se-kota Mataram. Terdapat 3 (tiga) actor yaitu pasien PKIA, bidan, dan petugas pendaftaran puskesmas. Kebutuhan fungsionalitas masing-masing actor dijelaskan pada Tabel 2 yaitu pada kolom SaaS.

\begin{tabular}{|c|c|c|}
\hline no & pengguna & SaaS \\
\hline 1 & Bidan & $\begin{array}{l}\text { Dapat melihat riwayat pasien yang terdiri } \\
\text { dari : data pasien, anamnesa, pemeriksaan } \\
\text { fisik, diagnosa, dan tindakan yang telah } \\
\text { diberikan kepada pasien. } \\
\text { Dapat menginput pemeriksaan yang } \\
\text { terdiri dari anamnesa dan pemeriksaan } \\
\text { fisik. }\end{array}$ \\
\hline 2 & Pasien & $\begin{array}{l}\text { Dapat melihat riwayat pasien yang terdiri } \\
\text { dari daftar pasien, data pasien, hasil } \\
\text { anamnesa, pemeriksaan fisik, diagnosa, } \\
\text { dan tindakan. }\end{array}$ \\
\hline 3 & $\begin{array}{l}\text { Petugas } \\
\text { pendaftaran }\end{array}$ & $\begin{array}{l}\text { Dapat menginput atau memvalidasi data } \\
\text { pasien }\end{array}$ \\
\hline
\end{tabular}

\subsection{Analisis Service Oriented Architecture (SOA)}

SOA merupakan pendekatan bisnis yang digunakan untuk arsitektur proses bisnis perusahaan agar bersifat reuseble, inter-changeble, dan terdapat black-box komponen software. Pendekatan SOA pada SaaS digunakan agar aplikasi bersifat reusable dan interoperable. Aplikasi yang bersifat reusable akan memudahkan dalam pembangunan aplikasi yang baru. Interoperable digunakan ketika informasi dari PKIA diperlukan oleh berbagai instansi atau pengguna lain di luar puskesmas.

Tahap awal dalam melakukan analisis SOA adalah menentukan kandidat service. Pada SOA, kandidat service dikelompokan ke dalam 3 (tiga) layer yaitu : Orchestration Service layer, business service layer dan application service layer. Berdasarkan proses bisnis PKIA terdapat beberapa proses yang dapat dijadikan sebagai kandidat orchestration service layer yaitu :

- Proses menginput data pasien

- Proses melakukan pendaftaran

- Proses melihat perawatan

- Proses melihat riwayat pasien

- Proses membuat rujukan

- Proses melakukan input hasil pemeriksaan antenatal 
- Proses melakukan input tindakan persalinan dan kondisi fisik bayi baru lahir

- $\quad$ Proses melakukan input hasil pemeriksaan kesehatan Ibu Nifas

- Proses melakukan input hasil pemeriksaan neonatus

- $\quad$ Proses melakukan input hasil pemeriksaan PONED neonatus

- Proses melakukan input hasil pemeriksaan PONED obstetri

- Proses melakukan input hasil pemeriksaan kesehatan bayi

- Proses melakukan input hasil pemeriksaan kesehatan balita

- Proses melakukan input metode kontrasepsi (KB) yang sesuai bagi pasien

Kandidat business service dan Application service yang diturunkan dari orchestration service sistem PKIA dapat dilihat pada Tabel 3.

\begin{tabular}{|c|c|c|}
\hline no & $\begin{array}{c}\text { business } \\
\text { service }\end{array}$ & application service \\
\hline 1 & $\begin{array}{l}\text { Service data } \\
\text { pasien }\end{array}$ & $\begin{array}{l}\text { Service menambah data pasien } \\
\text { Service melihat data pasien } \\
\text { Service mencari data pasien }\end{array}$ \\
\hline 2 & $\begin{array}{l}\text { Service } \\
\text { anamnesa }\end{array}$ & $\begin{array}{l}\text { Service menambah anamnesa } \\
\text { Service melihat anamnesa }\end{array}$ \\
\hline 3 & $\begin{array}{l}\text { Service } \\
\text { pemeriksaan } \\
\text { antenatal }\end{array}$ & $\begin{array}{l}\text { Service menambah pemeriksaan antenatal } \\
\text { Service melihat pemeriksaan antenatal }\end{array}$ \\
\hline 4 & $\begin{array}{l}\text { Service } \\
\text { pemeriksaan } \\
\text { persalinan }\end{array}$ & $\begin{array}{l}\text { Service menambah pemeriksaan persalinan } \\
\text { Service melihat pemeriksaan persalinan }\end{array}$ \\
\hline 5 & $\begin{array}{l}\text { Service } \\
\text { pemeriksaan } \\
\text { kesehatan ibu } \\
\text { nifas }\end{array}$ & $\begin{array}{l}\text { Service menambah pemeriksaan kesehatan } \\
\text { ibu nifas } \\
\text { Service melihat pemeriksaan kesehatan ibu } \\
\text { nifas }\end{array}$ \\
\hline 6 & $\begin{array}{l}\text { Service } \\
\text { pemeriksaan } \\
\text { neonatus }\end{array}$ & $\begin{array}{l}\text { Service menambah pemeriksaan neonatus } \\
\text { Service melihat pemeriksaan neonatus }\end{array}$ \\
\hline 7 & $\begin{array}{l}\text { Service } \\
\text { pemeriksaan } \\
\text { PONED } \\
\text { neonatus }\end{array}$ & $\begin{array}{l}\text { Service menambah pemeriksaan PONED } \\
\text { neonatus } \\
\text { Service melihat pemeriksaan PONED } \\
\text { neonatus }\end{array}$ \\
\hline 8 & $\begin{array}{l}\text { Service } \\
\text { pemeriksaan } \\
\text { PONED obstetri }\end{array}$ & $\begin{array}{l}\text { Service menambah pemeriksaan PONED } \\
\text { obstetri } \\
\text { Service melihat pemeriksaan PONED } \\
\text { obstetri }\end{array}$ \\
\hline 9 & $\begin{array}{l}\text { Service } \\
\text { pemeriksaan } \\
\text { kesehatan bayi }\end{array}$ & $\begin{array}{l}\text { Service menambah pemeriksaan kesehatan } \\
\text { bayi } \\
\text { Service melihat pemeriksaan kesehatan } \\
\text { bayi }\end{array}$ \\
\hline 10 & $\begin{array}{l}\text { Service } \\
\text { pemeriksaan } \\
\text { kesehatan balita }\end{array}$ & $\begin{array}{l}\text { Service menambah pemeriksaan kesehatan } \\
\text { balita } \\
\text { Service melihat pemeriksaan kesehatan } \\
\text { balita }\end{array}$ \\
\hline 11 & $\begin{array}{l}\text { Service } \\
\text { pemeriksaan } \\
\text { KB }\end{array}$ & $\begin{array}{l}\text { Service menambah pemeriksaan KB } \\
\text { Service melihat pemeriksaan } \mathrm{KB}\end{array}$ \\
\hline
\end{tabular}

\section{HASIL DAN PEMBAHASAN}

Pada bagian ini akan dijelaskan mengenai sistem yang berjalan dan perancangan SaaS yang diusulkan. Pembahasan akan dijelaskan pada sub bab 3.1 dan sub bab 3.2.

\subsection{Sistem Yang Sedang Berjalan}

Berikut ini merupakan hasil analisis sistem yang sedang berjalan:

- Data pasien tersimpan di masing-masing Puskesmas dimana pasien tersebut mendaftar.

- Pasien harus datang ke Puskesmas jika ingin melakukan pendaftaran layanan kesehatan.

- Pasien harus melakukan pendaftaran ulang sebagai pasien baru jika ingin ke Puskesmas di wilayah lain.

- Pasien masih menggunakan buku catatan kesehatan untuk melihat informasi dan pemantauan (monitoring) mengenai aktifitas kesehatan yang akan dilakukannya sehingga ada kemungkinan resiko kehilangan atau rusak.

Puskesmas belum memiliki data center, pencatatan dan pengolahan data masih dilakukan secara konvensional di masing-masing bagian baik itu data pasien maupun data yang dimiliki oleh puskesmas sendiri. Hal ini juga dikarenakan di tiap puskesmas tidak memiliki tenaga IT yang profesional.

\subsection{Perancangan SaaS Yang Diusulkan}

Bagian ini akan menjelaskan perancangan yang diusulkan pada penelitian ini yang meliputi perancangan use case diagram dan perancangan web service. Masing-masing perancangan tersebut akan dijelaskan pada sub bab 3.2.1 dan sub bab 3.2.2.

\subsubsection{Perancangan Use Case Diagram}

Use case diagram digunakan untuk menggambarkan interaksi pengguna dengan sistem PKIA. Rancangan use case diagram sistem PKIA ditunjukkan pada Gambar 2.

Gambar 2 merupakan rancangan use case diagram yang menggambarkan interaksi antara actor yaitu pengguna sistem dengan sistem yang akan dibangun. Pada sistem PKIA ini terdiri dari 3 (tiga) actor yaitu pasien, bidan, dan petugas puskesmas.

Melalui aplikasi yang akan dibangun nantinya yang merupakan bagian dari Software as a Service $(\mathrm{SaaS})$, pasien dapat melakukan pendaftaran layanan kesehatan di Puskesmas mana saja dan kapan saja tanpa harus datang ke Puskesmas yang dituju karena aplikasi yang akan dibangun nantinya berupa aplikasi mobile yang dapat di-install pada smartphone pasien. Ketika pasien datang ke puskesmas yang dituju, maka petugas puskesmas akan melakukan validasi terhadap data pasien tersebut 


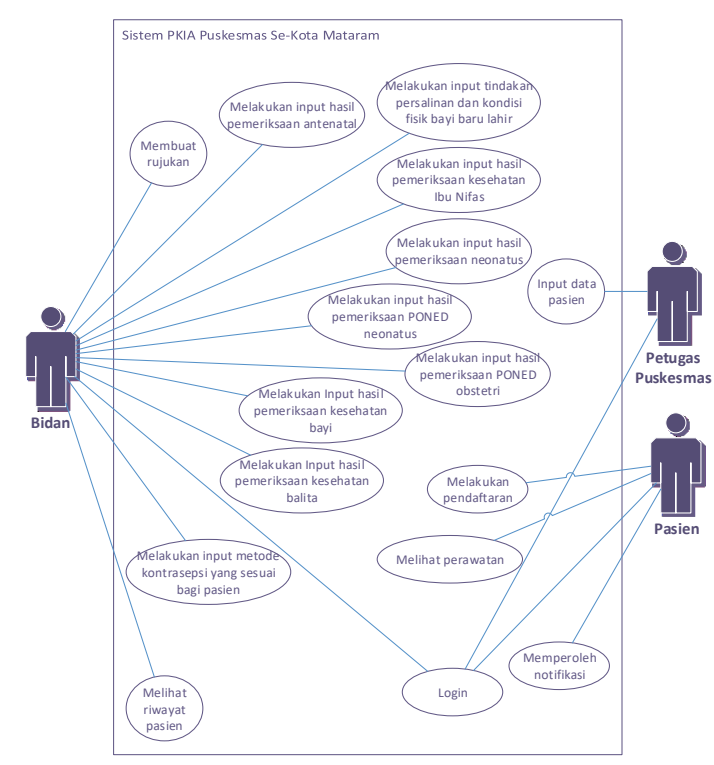

Gambar 2. Perancangan use case diagram sistem PKIA

Jika pasien belum pernah ke puskesmas manapun, maka pasien harus datang untuk melakukan pendaftaran sebagai pasien baru yang dapat dilakukan di puskesmas mana saja, pendaftaran sebagai pasien baru cukup dilakukan sekali saja karena datanya akan tersimpan secara terpusat di data center. Pasien juga dapat melihat jadwal kontrol dan melihat perawatan yang sedang dijalaninya melalui fasilitas yang terdapat pada aplikasi. Petugas puskesmas dapat mengelola data pasien, mengelola data rekam medis pasien, dan melihat data rekam medis pasien. Semua Bidan yang berada di seluruh puskesmas yang terdapat di wilayah Kota Mataram memiliki hak akses untuk melakukan input hasil pemeriksaan pasien sesuai dengan 9 (sembilan) layanan KIA. Bidan dapat melihat data riwayat rekam medis pasien. Bidan juga dapat membuat rujukan jika diperlukan.

\subsubsection{Perancangan Web Service}

SOA secara esensial adalah koleksi dari service yang saling berkomunikasi. Web service merupakan teknologi koneksi untuk mengimplementasikan SOA. Web service menggunakan Extensible Markup Language (XML) untuk membuat koneksi yang sempurna. Business service dan application service berdasarkan hasil analisis dibuat menggunakan web service. Teknologi yang digunakan untuk membangun web service pada rancangan ini menggunakan Java API for XML (JAXWS). Web service tersebut ditunjukan pada pada Tabel 4.

\begin{tabular}{cll}
\multicolumn{2}{c}{ Tabel 4. Perancangan web service sistem PKIA } \\
\hline no & nama business service & nama application service \\
\hline \multirow{2}{*}{1} & ServiceData Pasien & $\begin{array}{l}\text { AddPasien } \\
\text { ViewPasien } \\
\text { FindPasien }\end{array}$ \\
& & AddAnamnesa \\
2 & ServiceAnamnesa & ViewAnamnesa \\
& & AddAntenatal \\
\hline
\end{tabular}

\begin{tabular}{|c|c|c|}
\hline no & nama business service & nama application service \\
\hline & & ViewAntenatal \\
\hline 4 & ServicePersalinan & $\begin{array}{l}\text { AddPersalinan } \\
\text { ViewPersalinan }\end{array}$ \\
\hline 5 & ServiceIbuNifas & $\begin{array}{l}\text { AddIbuNifas } \\
\text { ViewIbuNifas }\end{array}$ \\
\hline 6 & ServiceNeonatus & $\begin{array}{l}\text { AddNeonatus } \\
\text { ViewNeonatus }\end{array}$ \\
\hline 7 & ServicePONEDneonatus & $\begin{array}{l}\text { AddPONEDNeonatus } \\
\text { ViewPONEDNeonatus }\end{array}$ \\
\hline 8 & ServicePONEDobstetri & $\begin{array}{l}\text { AddPONEDObstetri } \\
\text { ViewPONEDObstetri }\end{array}$ \\
\hline 9 & ServiceKesehatanBayi & $\begin{array}{l}\text { AddKesehatanBayi } \\
\text { ViewKesehatanBayi }\end{array}$ \\
\hline 10 & ServiceKesehatanBalita & $\begin{array}{l}\text { AddKesehatanBalita } \\
\text { ViewKesehatanBalita }\end{array}$ \\
\hline 11 & ServiceKB & $\begin{array}{l}\text { AddKB } \\
\text { ViewKB }\end{array}$ \\
\hline
\end{tabular}

\section{SIMPULAN}

Simpulan yang diperoleh berdasarkan hasil penelitian yang telah dilakukan (kuesioner, wawancara, studi literatur, dan perancangan) yaitu :

1. Sistem PKIA puskesmas berbasis cloud SaaS berdasarkan hasil survey dan wawancara dengan pihak terkait pada penelitian ini ternyata sangat diminati karena faktor mudah dan murah dari segi biaya, waktu, dan tenaga.

2. Sisi privasi sangat diutamakan. Pihak puskesmas tidak ingin data pasien dapat diakses oleh oknum yang tidak bertanggung jawab.

3. Sistem PKIA puskesmas berbasis cloud SaaS diharapkan mampu menyelesaikan masalah untuk keterbatasan biaya, waktu, dan tenaga bagi setiap puskesmas di kota Mataram.

4. Pemanfaatan SOA pada SaaS akan memudahkan dalam integrasi sistem PKIA Puskesmas.

5. Hasil akhir penelitian ini berupa hasil analisis kebutuhan berdasarkan permasalahan yang terjadi di lapangan beserta perancangan yang dibuat diharapkan dapat dijadikan dasar dalam implementasi perangkat lunak sistem PKIA Puskesmas se-Kota Mataram berbasis cloud SaaS.

6. Berdasarkan hasil wawancara yang telah dilakukan dengan beberapa pasien dan pihak Puskesmas yang terdiri dari bidan dan petugas, hasil rancangan ini telah sesuai dengan apa yang diharapkan. 


\section{DAFTAR PUSTAKA}

AFWANI, R., 2017. Rancang Bangun Arsitektur Berorientasi Layanan untuk Sistem Informasi Bergerak Pelayanan Kesehatan Ibu dan Anak di Provinsi NTB. Laporan Penelitian Terapan Universitas Mataram.

ARMBRUST, M., FOX, A., GRIFFITH, R., JOSEPH, A.D., KATZ, R., KONWINSKI, A., LEE, G., PATTERSON, D. dan RABKIN, A., 2010. A View of Cloud Computing Clearing. Communications of the ACM, 53(4).

AYUNINGSIH, I., PERMANA, D. dan HERMAWAN, D., 2015. Implementasi Software as a Service Pada Sistem Layanan Klinik Kesehatan. Jurnal Online Sistem Informasi (JOSINFO) Program Studi Sistem Informasi STMIK STIKOM Bali, 1(1).

BALBONI, P., 2009. Cloud computing for e-health data protection issues. European Networks and Information Security Agency (ENISA), pp.97-111.

JATMIKA, A.H. dan AFWANI, R., 2018. Analisis Dan Perancangan Arsitektur Community Cloud Computing Untuk Menunjang Pelayanan Kesehatan Ibu Dan Anak ( Studi Kasus: Puskesmas Se-Kota Mataram ) Analysis And Design Of Community Cloud Computing Architecture To Support Maternal And Child Health S. Jurnal Teknologi Informasi dan Ilmu Komputer, 5(1), pp.51-56.

KUSDIANA, G., 2014. Perancangan Dan Implementasi Teknologi Cloud Computing dengan Layanan Software As A Service (SaaS), Platform As A Service (PaaS), Infrastructure As A Service (IaaS) Pada Sistem Informasi Rumah Sakit (SIRS) Sebagai Pelayanan Kesehatan. Skripsi S1 Teknik Informatika Universitas Komputer Indonesia.

SUKAMTO, R.A. dan SHALAHUDDIN, M., 2018. Rekayasa Perangkat Lunak Terstruktur dan Berorientasi Objek (Edisi Revisi).

TONI, K., 2012. Arsitektur Software As a Service Saas Pada Layanan Rumah Sakit. Jurnal Computech \& Bisnis, 6(1), pp.17-26. 